\title{
O jovem Moravia
}

Raffaele Manica

Carla tem setenta anos. Era 1929 quando um narrador estreante nos fez saber que, fechando a porta, a sua saia curta de lã marrom subiu rapidamente sobre as meias (estava às vésperas de seu vigésimo quarto aniversário, mas para a anágrafe literária tem setenta anos). ${ }^{1}$

A entrada de Carla dava início a uma "tragédia em forma de romance" (recorda Enzo Siciliano). Carla mudou, portanto, a história do romance italiano; depois disso Moravia tornou-se um grande autor do século XX; mais tarde foi deslocado, porque a um certo ponto criou-se a ilusão, na reflexão crítica e na sistematização histórica, de que a substância e o sangue das nossas letras estivessem nos, assim chamados, menores. Com certeza estavam ali também, mas parece árduo imaginar o século XX italiano sem Moravia. "Entrou Carla" e a literatura penetrava em alguma parte ainda não vista, encontrava-se no pós-Svevo, que havia dado voz à Coscienza di Zeno seis anos antes, em 1923. Encontrava-se também nos territórios do escrever mal.

Aquilo que é mais fascinante na viagem, dirá Moravia já velho, é “o desconhecido. Disse-o Baudelaire, de outro modo: 'Au fond de l'inconnu / chercher du nouveau'. A união do desconhecido com o novo”. Nos anos que vão de 1929 a 1937, ou ainda de Gli Indifferenti às Ambiz̨ioni Sbagliate, Moravia escreve um amplo conjunto de artigos de viagem: Inglaterra (1930-1932), Tchecoslováquia (1931), França (1932), Estados Unidos e México (1936), China (1937). Confrontando esses artigos com aqueles mais tardios, vê-se com clareza que Moravia aprendeu a sua secura lendária com o tempo; e com o tempo aprendeu a arte da simplificação capaz de não negligenciar as razões da complexidade. A força das idéias simples, início de um magistério que não terá epígonos, parte daqui, mas tem muito que percorrer antes de amadurecer.

O horizonte, o panorama que Moravia tem diante de si quando começa a escrever sobre viagens é aquele dos enviados especiais dos anos 20, enquanto se forma em torno dele, nos nascentes anos 30, a nova paisagem dos literatos em movimento: o gênero, se de gênero se trata, das travel literature, que só os grandes escritores sabem transcender e transformar em alguma outra coisa. Será preciso a escrita sensual e plástica, cheia de impulsos, densa das imagens e sensações de Giovanni Comisso, para mudar o curso das coisas. Com Comisso, a cultura de viagem começa a fazer parte da autobiografia: uma nova dimensão.

Moravia adquirirá um modo próprio de escrever sobre viagem, contrapondo ao traço suave do desenho de Comisso com as cores à De Pisis, o esboço a lápis que cria chiaroscuri a partir do traço forte, evitando induzir a reformulações ou rasuras. Naquele momento, a paisagem dos anos 30 apresenta-lhe uma linha que margeia a prosa de arte, uma linha de marca especialmente rondista, com notáveis e freqüentes sinais vocianos, resolvida 
posteriormente em composição solariana. Depois dos Oriani e dos Panzini, ${ }^{2}$ isto é, depois de algumas viagens que parecem de uma outra época, passando pelas páginas já diversas dos livros de Luigi Barzini e de Gian Gaspare Napolitano, ${ }^{3}$ já superada a metade dos anos 30, Giuseppe Antonio Borgese (Autunno di Constantinopoli, 1929) abre a estrada para Viaggio in Turchia (1932), de Corrado Alvaro, que logo publicará I Maestri di Diluvio. Viaggio nella Russia Sovietica (1935); Massimo Bontempelli recolherá em 1942, em Stato di Grazia, dois pequenos volumes: Noi, gli Aria (1934) e Pezzi di Mondo (1936). O caderno africano de Bruno Barilli é já dos anos 40, o qual será lembrado como antepassado muito distante, mas de um outro ramo familiar, pelo estilo e modo de sentir, dos livros que testemunham a última grande paixão geográfica de Moravia: Il Sole in Trappola, de 1941. Viaggi nel Tempo, de Cardarelli, data de 1920, o mais antigo caderno de anotações. Tampouco se poderá esquecer Le ragazze di Tokyo, de Ercole Patti (1934, retomado cerca de quarenta anos mais tarde com novo título, Un Lungo Viaggio Lontano).

Bem mais que no seu romance de estréia, nas primeiras relações de viagem Moravia tem a mão do literato, propenso às tradições recentes. Em particular, a correspondência inglesa sustenta a impostação que transforma os traços em narração. Breves contos, centrados sobre as relações entre o autor e os lugares visitados, sem exigências de resultados objetivos. Aqui, e não nos romances ou nos contos de Bella Vita ou de Imbroglio, é mais intensa a herança ou a pesquisa de literariedade na articulação e na impostação da voz. A resposta aos críticos que o haviam acusado de achatamento da prosa começa antes da publicação de Ambiz̨ione Sbagliate.

Leia-se o incipit aquático de Arrivo a Londra, a imagem de efeito que dá início aos movimentos de uma prosa vivaz, a seu modo alegre no uso das adjetivações preciosas e amaneiradas. Prosa verbalmente frenética, ou mesmo excitada no seu período longo embora retardado, com a pressa de quem passa de trem e move os olhos continuamente, à procura de um ponto que resuma ou que revele um primeiro sentido (sentimental ou racional) do novo lugar, às voltas com involuntárias abluções. A pontuação é reduzida ao mínimo, por exigência do ritmo, enquanto que aos lugares vistos pouco antes se sobrepõem a sua lembrança no presente, fundindo os planos temporais:

\footnotetext{
Muita terra francesa que atravessei estava sob a água. Através da janelinha do compartimento, via-se até onde os olhos alcançavam uma paisagem misteriosa, na qual as sebes e as árvores que deveriam servir para limitar os campos ao invés disso subdividiam imóveis espelhos d'água. A inundação havia chegado até a estrada de ferro, escalando pelos sulcos brilhantes a encosta do terreno e agora, imóvel, e como que satisfeita refletia sem um só tremor os choupos melancólicos, o céu branco, as fazendas baixas de tetos inclinados. Em Paris, ao contrário, vi aquela mesma água tão tranqüila espumar amarela e violenta no Sena durante a cheia".
}

Também a correspondência francesa mantém vivo este tom (incluído o tópico pucciniano, "sgelo" primaveril de Paris, em Moravia "degelo" mais comedido na viagem tchecoslovaca. Mas se trata de três cadernos de anotações contemporâneos, já que o da Inglaterra tem como data 1930-1932, incluindo o de 1931, tchecoslovaco e acrescentando no final, o de1932, da França. 
Mil novecentos e trinta e seis é o ano do caderno de anotações americano. Aqui Moravia encontrava referências ilustres. Do mesmo ano é o Atlante Americano de Borgese, precedido em um ano por America Primo Amore, de Mario Soldati; e já se apresenta no horizonte America Amara, de Emilio Cecchi (1939, precedido de Messico, de 1932, em uma dobradinha que é a mesma de Moravia. A história do livro de Cecchi é elaborada, mas basta dizer que foi iniciado exatamente nos anos de Messico). Este é o contexto no qual nasce também Neve a Manhattan, de Quarantotti Gambini (criado a partir de uma viagem de 1939 e que permaneceu inédito até 1998); mais de dez anos depois surgirão os textos de Giuseppe Prezzolini (America in Pantofole, 1950, e America con gli Stivali, 1954) e o vasto afresco de De America, de Guido Piovene (1953), livros que são relembrados porque coincidem temporalmente com o segundo caderno de anotações americano de Moravia, de 1935.

As datas de edição dos livros de viagem estão entre as poucas coisas seguras, e são o único ponto de apoio, para comparações e referências.

O crescimento de títulos sobre os Estados Unidos naquele momento tem relação com a retomada econômica do país, depois da derrocada de Wall Street de 1929. O que seguirá a partir daí é a celebração da vida incomparável e maravilhosa (para usar adjetivos comuns nos títulos dos filmes dos ítalo-americanos La Cava e Capra - My Man Godfrey [L'Impareggiabile Godfrey] é de 1936, It's a wonderful life [La vita é meravigliosa] de dez anos depois, quando não só a América será tomada por uma outra crise ainda maior ${ }^{4}$ ) e laboriosa, entre astúcias e paixões, como Soldati fixa irrequieto nas suas páginas:

Correm, sentam-se e simultaneamente comem um sanduíche, lêem um livro, fumam um cigarro, bebem café com leite [...] Este Oriente, essa mistura de Nápoles e Constantinopla, de Varsóvia e de Dublim, de Hamburgo e de Atenas. Essa confiante Jerusalém das misérias européias, Sixth Avenue.

É a vida entre as duas guerras, e Nova Iorque, como Wall Street, é um horóscopo dentro do qual se pode prognosticar vidas e afetos individuais retirados do nome da cidade. Se Soldati escreve: "E quando eu abaixava o olhar, via a massa difusa dos cabelos loiros que lhe escondiam o rosto. Eu não pensava estar abraçando uma mulher. Mas uma americana."; Moravia (Le Americane) vai às raízes, à escassez de mulheres na primeira colonização: é por isso que agora a América é "o paraíso da mulher". E se esconde aqui, em um detalhe significativo, a diferença entre as duas vozes.

A China, o continente misterioso e mítico nas letras italianas (de Marco Polo aos Jesuítas, além de outros), é o país distante por excelência, porém próximo por tradição e, se poderia dizer, domesticamente estranho, como o exótico de manual. Enrico Emanuelli, no título de sua reportage (1957), La Cina é Vicina, chama a nossa atenção para isso. Acrescentese ainda que, pela ideologização do século, dos anos 50 em diante, a China será uma terra prometida, devido ao seu comunismo igualitário, repleto de homens, pululante de vidas e próspero de sabedoria.

Com isso, na sua viagem pré-revolucionária, faz com que as questões de viscosidade política lhe escorram pelo corpo, tornando-as desinfetadas. Talvez não perceba nem mesmo o que significam, nem quanto valem. Não se importa com as contingências da história; é um antropólogo brincalhão: caso tivesse que se sentir historiador por dever de ofício - 
mas não parece que deste dever se conservem traços - seria daqueles de longa distância, de questões das mentalidades. Parece que, viajando na China, mantém intacto o estupor que nos toma quando, ao despertar, encontramo-nos em um leito diverso do habitual, e, assim que abrimos os olhos, gastamos um certo tempo pensando nisso, antes de nos conectarmos ao dia e de reencontrarmos as coordenadas do espaço. O conhecimento para Comisso se dá por impulsos infantis, portanto se maravilha sempre do mesmo modo, quer se encontre em Nápoles ou em Pequim. No entanto, apesar de se maravilhar, compreende muito bem que se encontra em Pequim e não em Nápoles: é alguém que levanta sempre as orelhas, alarga as narinas à espera de odores, e arregala os olhos à espera das cores do dia.

A viagem de Comisso (1929-1930), narrada (em volume) em Amori d'Oriente, em Gioco d'Infanzia e enfim em Le Mie Stagioni, foi uma viagem poética. A viagem de Moravia (1937) assinala no escritor de trinta anos um ponto de mudança. Sua prosa não está distante das rajadas literárias que atingiam Londres e Paris, mas cria uma dicção diferente, como se a literariedade fosse um fardo cansativo, um daqueles objetos comprados em viagem que pesam e para os quais não se vê função quando se volta para casa. A idéia literária de misturar Manzoni e Dostoiévski, remédio presumido para o presumido achatamento, estava por se exaurir em Ambizioni Sbagliate (iniciado em 1928 e reescrito até 1934) e se encaminhava para a conclusão. A secura será reencontrada em Agostino (1943).

No jovem escritor estão presentes, e expressos em grau máximo, todos os temas da sua individualidade, ainda que futura; outros, de alcance diverso, serão acrescentados pelos sucessivos contextos, ou mesmo pela História (da alienação ao terrorismo - a famosa pistola emperrada dos Indifferenti disparará bem mais tarde, na Vita Interiore, quando a revolta se travestirá de ilusão revolucionária, procurando um álibi - até o maneirismo final de 1934 e de Viaggio a Roma).

No início, as chaves de leitura do mundo são duas: sexo e dinheiro, enquanto na seqüência será o sexo, cada vez mais, que dará sentido ou falta de sentido ao mundo, centrifugando o resto. Mas se aqui há o dinheiro, quer dizer que há também o resíduo dos romances do século XIX, de Balzac a Verga. Gli Indifferenti, onde as duas chaves coabitam, é o livro no qual Moravia marca a passagem do século XIX, amado como leitor, para o século XX, que contribui para fundar. Todavia, sobre a atividade daqueles anos, adensa-se como uma nuvem de forma curiosa, de ambígua interpenetração, um julgamento posterior de Moravia:

Nunca mais escrevi, depois de Gli Indifferenti, salvo 'Inverno di Malato', algo tão fundamental, até 1942, ano em que, em Anacapri, reencontrei a minha inspiração originária e escrevi Agostino. Foi, portanto, um longo trabalho entre experimentação e impotência. O que tenho portanto a dizer sobre a precocidade é o seguinte: se Rimbaud, ao invés de vagabundear pelo mundo, depois de ter escrito as poesias, tivesse permanecido com sua mãe, não acredita que the teria acontecido algo parecido, isto é, que teria escrito de outro modo o que escrevera nas poesias? É uma observação que pode parecer presunçosa, mas na realidade não diz respeito ao talento, mas à precocidade. Durante quinze anos, eu não tive nada a dizer. Ocorreu-me que o silêncio de Rimbaud pudesse ser imputado provavelmente a sua extraordinária precocidade. Naturalmente trata-se de uma hipótese como qualquer outra para explicar psicologicamente um mistério literário que ainda fascina críticos e leitores. ${ }^{5}$ 
Como é difícil acreditar que o autojulgamento negativo possa dizer respeito aos contos, é possível que recaia sobre Ambizioni Sbagliate (1935) e sobre Mascheratta (1941). Em Le Ambizioni Sbagliate, como já foi dito, o que deve ser sublinhado é seu caráter literário: Moravia se apresentava em belo estilo, alterando vários registros da sua voz, como uma multa a ser paga por causa de Gli Indifferenti. Os romances que renovaram o nosso século $\mathrm{XX}$, como se sabe, sofreram com freqüência a mesma acusação de mau estilo. O belo estilo nada mais sendo que a acomodação a um modo pré-existente.

Aqui um desvio para as paragens de Tommaso Landolfi, sobre o fundo curiosamente naturalístico de seu primeiro período. Curiosamente porque o naturalismo de Landolfi é falso: poucos escritores se desinteressaram de modo tão cabal pelo realismo. Esse aparente naturalismo com desinteresse pelo realismo é um registro adotado pelos seus modos tópicos. Se realismo é, antes de mais nada, uma escolha de registros estilísticos e de planos lingüísticos que incluem como corpo sonoro e baixo contínuo o naturalismo, Landolfi, de todos os registros possíveis do realismo, adota o registro de preenchimento, e é este que sustenta todos os outros. A sua rodada de naturalismo consiste no enxugamento do realismo. Assistese a uma sobrevivência do naturalismo, projetado como sombras que alteram suas dimensões, como no pôr-do-sol. Com Landolfi e outros escritores dos anos 30, há uma projeção do naturalismo em outra sede (considere-se o triunfo do "eu" romanesco em Soldati). Moravia inicialmente operava na mesma direção, mas o enxugamento do realismo visava exaltar a sua essência primária, até à objetividade e ao cancelamento da voz do autor.

O primeiro conto de Landolfi traz, ao pé da página, a data de 1929, que é a mesma da publicação de Gli Indifferenti.

De 1935, ao que parece, é Mani, do livro Dialogo dei Massimi Sistemi, com o exórdio, "Federico tornava a entrar" (freqüentemente se torna a entrar no início dos contos de Landolfi, ou há alguma porta ou soleira a ser transposta, como se tudo, também narrativamente, estivesse, naquele momento, se fechando, ao invés de se abrir; como se Landolfi, preferindo lugares fechados, ao contrário de narrar, preferisse bater a porta. $\mathrm{O}$ tio de Pietra Lunare convida a entrar; "O advogado Coracaglina voltava para casa" no Mar delle Blatte; há poucas semanas, Carlino havia retornado em Ragazze di Provincia; e assim por diante. Todos tornam a entrar porque alguma coisa está para acontecer, mas não do lado de fora, mas exatamente ali onde se entra de novo). Dizia-se, "Federico torna a entrar", que se encontra em quiasmo com "Entrou Carla" e que, caso se quisesse insistir, sem possibilidade de prova e por puro gosto da coincidência (sem esse gosto a literatura perde muito), poder-se-ia chamar de uma microparódia.

Mesmo que se deixe a hipótese de lado por ser incongruente, permanace o fato que em Landolfi, como em Moravia, o lugar é fechado, teatral como uma cena elisabetana, e até a aparição do sangue não se sabe se é tragédia ou comédia.

Moravia e Landolfi estavam separados, segundo a anágrafe literária, por um ano, 1907 e 1908. Tinham lido os mesmos livros, os russos e os franceses, obrigatórios para quem se dirigia para prosa de invenção: mesmo Federico, entrando novamente, lê as gestas de seu homônimo, Frédéric Moreau em A Educação Sentimental, enquanto está para se inaugurar a sua educação sentimental com os ratos. 
Moravia publicou pela primeira vez em 1929; Landolfi em 1937, sendo seu capítulo mais antigo, a Maria Giuseppa, datado de 1929. Em 1937, Moravia tinha atrás de si dois romances, duas coletâneas de contos, uma meia dúzia das suas viagens; uma resposta vitalista à doença, um pouco ditada pela euforia da convalescença, mas, principalmente, já havia escrito sobre a "nudez esquálida e furiosa" em Delitto al Circolo del Tennis, que tem um parentesco identificável com a postura psicológica de Maria Giuseppa. Em ambos a sexualidade vem escandida de uma maneira triste e quase, pode-se dizer, ao ritmo de uma marcha fúnebre: um ponto grumoso e imperscrutável devido à obscuridade.

A “obscuridade" em Landolfi é dada pelos pontos de deformação, aqueles nos quais o eixo das palavras começa a se deslocar do eixo das percepções, e o eixo das percepções, por sua vez, se desloca da natureza das coisas. Esses pontos aparecem, não atenuados, mas diversamente orientados e iluminados em Moravia.

Le Due Zitelle, obra mais tardia na cronologia do catálogo landolfiano, de 1946, mostra sua persistência. Cinza e de província, a casa de Landolfi; cinza e da capital, a de Moravia. Da alta densidade de homens, animais, coisas, no primeiro, à baixa densidade de homens e coisas, no outro; primeiros planos em um e no outro (planos muito próximos, de detalhes); fisionomias grotescas em ambos, mas com animalização em Landolfi, e, ao contrário, com acentuação caricatural dos traços humanos em Moravia. É o quanto basta para confirmar, com olhar de quem veio depois, a possibilidade daquele quiasmo. E, talvez, a origem daquele grumo.

Em 1922, solene e gorducho, Buck Mulligan havia entrado em Ulysses, com sua bacia de espuma, seu espelho e sua navalha. Diz Moravia:

Joyce havia cunhado a palavra epifania, eu prefiro iluminação, que é o termo predileto de Rimbaud. O que é a iluminação? Chego aqui a um ponto mais interessante ainda, e só eu posso afirmá-lo. A iluminação é isto: uma operação racional de velocidade vertiginosa. Se você tem um ventilador em casa e o liga, a um certo ponto você não verá mais as pás, verá algo parecido com uma nuvem. Ora, a iluminação na realidade é uma aceleração fantástica da racionalidade. E isso é tão verdadeiro que os críticos, quando examinam alguma coisa de realmente belo, desmontam e analisam pedaço por pedaço o mecanismo fulgurante e racional da iluminação. Se assim não fosse, não seria possível fazer a crítica da obra de arte". 6

A relação do jovem Moravia com as literaturas estrangeiras aflora como uma paixão devoradora, e não será abandonada até os últimos dias. Em uma prosa de lendária secura, não se encontram homenagens, através de alusões ou de citações embutidas, a Baudelaire e Rimbaud, a Tolstói e Dostoiévski, enfim, aos grandes mestres da prosa. Tudo aquilo que foi conhecido pela leitura é um clima mental, um esvoaçar de pontos de referência, reabsorvidos dentro de uma tradição mais próxima, se aceitarmos que a homenagem alusiva mais explícita, na juventude, parece ser aquela cuja agnição se dá no jogo entre vítima e carrasco, entre Girolamo e Brambilla, em Inverno di Malato, no momento em que, o homem que troçava dele, burguezinho insignificante, se cura, Girolamo abandona-se às fantasias e caprichos de derrotado. É aqui então que Moravia o leva de volta à realidade com "O choque que fez o leito contra o umbral de seu quarto”. Choque que, o leitor já terá percebido, 
imita "O barulho que fez a barca contra a costa", sacudindo Lúcia e subtraindo-a do seu adeus aos montes no início do capítulo nove de Promessi Sposi; e que tem um eco no capítulo oitavo de Gli Indifferenti, quando Carla decide finalmente fugir com Leo:

Adeus estradas, bairro deserto percorrido pela chuva como por um exército, mansões adormecidas em seus jardins úmidos, longas alamedas arborizadas e parques em tumulto; adeus quarteirão alto e rico.

Um toque de classe, caso as reconstruções, afastados os contextos originários, introduzam-se sem atrito no novo casamento. Todo o resto, Moravia ou assimila ou deixa de lado. Ele é isento de exercício literário, porque converte a literatura em experiência, fonte de nutrição da escrita. E, de fato, quanto de Baudelaire escorre subterrâneo em Moravia, naqueles corpos de algum modo sempre desajeitados que nos descreve? Mais ainda, do adorado Rimbaud, o mito da adolescência e da primeira juventude: um companheiro de formação, uma escolta um pouco mais velha e desregrada. Baudelaire, ao contrário, aparece como um irmão maior, um moralista solidário, uma voz cujo timbre, escandindo uma vida atroz, organiza-a em uma retórica encantadora e sábia.

A França foi, para Moravia, a terra de Breton e dos surrealistas, de Apollinaire e Tzara, e em parte de Cocteau, a cujo rappel à l'ordre era desfavorável, como ao neoclassicismo, à art déco e a Valéry. Entre os surrealistas pintores, aprecia Max Ernst, a ponto de dizer que havia se inspirado em Une Semaine de Bonté para escrever muitos de seus contos. ${ }^{7}$

Da tríade famosa, o único verdadeiramente abandonado é Mallarmé. Isso já não acontece com Pasolini; basta pensar na presença de Mallarmé, de L'Azur, em Teorema, em que o Hóspede lê Rimbaud, e em que é claramente reconhecível a presença baudelairiana (Moravia: "Em Usignolo della Chiesa Cattolica é possível colher freqüentemente pastiches extraídos de Rimbaud. Rimbaud, o poeta da revolta, era-lhe muito apropriado" - dirigindose a Ajello ${ }^{8}$-; e depois: "O mestre de Pasolini foi a grande poesia européia, como, por exemplo, Rimbaud. Pasolini era europeu já em Casarsa, quando escrevia versos em friulano" - dirigindo-se a Elkann). ' Ao contrário, em Moravia os "precedentes são irreconhecíveis", assim como ele apontava para a presença de Baudelaire "espalhado no estilo de Cecchi” (a Ajello). ${ }^{10}$

Da residência para convalescentes de Bolzano, nos últimos meses de 1925 (em outubro, em Bressanone, Moravia fixou sobre um papel de seda a primeira frase de Gli Indifferenti; a última escreveu em 1928), a fresta para a contemporaneidade européia foi precocemente aberta: Proust e, logo depois, em Florença, Joyce, tramaram os fios sobre a tela de Dostoiévski, que representava para Moravia o tecido de conexão e a arte mesma de escrever.

Freud pairava no ar, já notado àquela altura, mas talvez ainda não encarado de frente. No entanto, é impossível contar as situações freudianamente elaboradas em Gli Indifferenti, a começar pela confusão iniciada com o gesto de ofensa de Michele, que, na tentativa de golpear Leo, acaba acertando a mãe com um cinzeiro: "procurava um pouco de piedade afetuosa por aquela figura imóvel, perdida no erro: a sua alma permanecia inerte", enquanto "os dedos impudicos" de Mariagrazia "pareciam perseguir um objetivo completamente diferente daquele de mostrar as feridas; por exemplo, o de despir-se", frente ao filho e ao amante. 
$\mathrm{Na}$ seqüência da cena, um substituto simbólico de Michele (um fetiche, um manequim vazio) golpeia Leo: movido pelo vento, por um sopro vital que vem de fora, "um leve sobretudo de Michele, pendurado no cabide, percorre várias vezes com suas longas mangas a face de Leo".

Mais adiante, com ciúmes de Pippo Berardi, o mesmo personagem Michele, em uma singular indiferença, ciumenta e deleitosa, recordará a irmã em uma cena de nudez, quando, saindo do banho, mostra seu "branco dorso curvo sob a grande cabeça indolente e molhada" e o seio "pende sob a axila morena".

E há, por fim, o prazer de Leo em humilhar as amadas ou em vê-las se humilharem. Mais que a sua apagada relação com Mariagrazia, falam as moedas para o táxi colocadas na mão de Carla depois da primeira noite entre eles; ou o prazer com o qual a vê abaixada sobre o tapete a recolher os pedaços do colar arrebentado pela enciumada Mariagrazia (em relação a Lisa). É Carla, a própria humilhada, a se perguntar: "de onde lhe vinha essa necessidade de se abaixar, de rastejar, de se esconder", enquanto Leo "considerava com divertimento as nádegas altas, móveis, arredondadas sobre o dorso côncavo e a cabeça quase ausente”. Cena de submissão repetida por Michele, que pensa em vender Lisa a Leo e em presentear-lhe Carla, pelo dinheiro necessário para quitar a hipoteca da casa, que Leo controla.

$\mathrm{Na}$ introdução a Romanzi e Racconti, 1929-1937, Siciliano ressalta mais pontos nos quais, através da nudez, os personagens do jovem Moravia descobrem ou alguma coisa de si ou algo que a realidade tinha até então escondido. Trata-se de Carla, que, sozinha no próprio quarto, começa a tremer: é o momento sucessivo ao beijo do amante, e ao desnudamento de Carla diante do espelho; ou se trata da já relembrada "nudez esquálida e furiosa" de Delitto al Circolo del Tennis.

Pode-se acrescentar ainda a presença de Carla no leito de Leo, sentindo-se nua sob os lençóis frios. Há alguma coisa, diz Siciliano, que torna ásperas as palavras, que "as inerva com um desconhecido peso físico, como se através delas abrisse caminho a erupção de uma matéria desconhecida. Essa matéria desconhecida é a sexualidade", coisa nova e diversa em relação ao erotismo. Essa sexualidade é angustiada, assim como a nudez é indício de vergonha: são lapsos, patologias da vida cotidiana. A Leo, sob a chuva, Carla reaparece "nua e chorosa", enquanto ele pensa em como desafogar-se fisicamente depois que ela se retrai; e, pensando na necessidade genital, ele vai se colocar sobre as "costas nuas" de Lisa, da qual erra significativamente o nome, chamando-a Maria, exatamente como Andrea Sperelli em Piacere (uma Maria também ali, que, em situação oposta, é chamada de Elena): e "Michele entrou". Mas e Maria? Uma apócope para Mariagrazia ou o nome da camareira de Lisa que aparece logo depois?

E o que diferencia Andreina, em Apparizione (data no rodapé: 1928), de Carla?

A porta se abriu e alguém entrou: Andreina. Trajava um elegante vestido com extremidades de pelica, apertado na cintura e largo embaixo, que the dava um aspecto agressivo; um pequeno chapéu em forma de elmo escondia-lhe os olhos; aquela costumeira expressão, não se sabia se estúpida ou digna, estava sobre o seu rosto estranhamente achatado, todo de frente, nada de perfil, com grandes ossos maxilares, boca larga, e olhos inexpressivos. 
Gaspare dirige-se a ela sem se mover. Quando entra Carla, Leo curva-se adiante. Em Apparizione, trata-se de um ícone católico, de uma imagem da Madona (e para mais afinidades, a memória pode resgatar Il Ricordo della Basca, que Delfini publicará em 1938). Em Gli Indifferenti, num cerco de luz,

os bibelôs e os outros objetos, ao contrário dos seus companheiros mortos e inconsistentes espalhados pela sombra da sala, revelavam todas as suas cores e a sua solidez": sobre aquela sombra, escreve a página seguinte, "lá embaixo, [daquela sombra] que preenchia a outra metade da sala, a onda morta do rancor moveu-se, deslizou pelo peito de Carla, desapareceu, negra e sem espuma; ela permaneceu com os olhos arregalados, sem fôlego, emudecida por aquela passagem de ódio.

O ícone oposto. Carla não responde à súbita oferta de Leo:

mexia com o dedo a cabeça móvel de uma porcelana chinesa: um burrico muito carregado sobre o qual, entre dois cestos, sentava-se uma espécie de Buda campesino, um camponês barrigudo envolto em um quimono florido; a cabeça subia e descia, e Carla, de olhos baixos, de faces iluminadas, de lábios apertados, parecia totalmente absorvida nessa ocupação.

Butterfly: "preguiçosos e obesos são os Deuses Japoneses". Mas Leo é muito mais um repugnante Rodolfo que um Pinkerton ("Que bela menina”, pensa duas vezes na cena do jardim; assim como Rodolfo pensa no sótão); e esse Buda não é um Buda, é um objeto que reflete à distância algum traço físico. Um talismã, um souvenir da indiferença. Leslie Fiedler, em Love and Death in the American Novel", observou de que maneira a "tirania da superstição", como a chamava,

longe de ser a criação de padres maquiavélicos, era a projeção de uma profunda falta de segurança interior e de um profundo senso de culpa, um oculto mundo de pesadelo não abolido dos manifestos nem expulso das barricadas. O máximo do horror, como a sociedade moderna é obrigada a constatar, não é provocado pelos deuses nem pelos demônios, mas pelos aspectos mais profundos da nossa mente.

No jovem Moravia, o único mal é aquele da alma, não existem males físicos, desconsiderando-se como tais a velhice da mulher em Cortigiana Stanca, coroada de um ambiente sepulcral (tal qual o escuro em Apparizione), e a da princesa no Delitto. E Cortigiana Stanca está em nexo estreito com a história de Lisa em Gli Indifferenti, até mesmo na conotação sepulcral. Veja-se o crucial capítulo sétimo, cena entre Michele e Lisa:

Entretanto, a sombra da sala aumentava, engolia as paredes e os móveis, adensava-se, baixava sobre os dois, escurecia tudo; uma caverna se formava, rudemente escavada na obscuridade, com uma abóbada baixa e fuliginosa, uma caverna de luz mortiça; e, curvas nesse halo moribundo, as duas figuras negras velavam o caixão sobre o qual os círios palpitavam, avermelhavam, escureciam... e finalmente se apagaram

O Delitto se conecta aos Indifferenti com a cena de baile no Ritz (no mesmo capítulo). Moravia é atraído pelos defeitos da realidade, como se de lá fosse possível ver novas realidades, à maneira das mulheres cantadas nas Flores do Mal. As iluminações chegam 
somente ao olhar do áugure, como a fileira de corvos sobre a neve em Inverno di Malato ou o céu cinzento de Gli Indifferenti.

Gli Indifferenti e, simbolicamente, toda a obra de Moravia inaugura-se com uma didascália, no passado. Depois há a questão do ponto e vírgula, no início (que antecipa uma presença estatística muito acentuada no romance inteiro). A literatura italiana, até então, ainda não havia conhecido alguém tão precocemente maduro. Aquilo que importa, todavia, é que aquele ponto e vírgula separa a didascália da ação, é a tradução romanesca do escrever para o teatro. Uma pausa e meia de suspensão. Em seguida o vestidinho de lã marrom torna-se protagonista da primeira cena de Gli Indifferenti: é o alvo primeiro de Leo e será ultrapassado e substituído pela presença física de Carla na cena atrás da cortina do vestíbulo, quando Mariagrazia, para evitar a Leo o encontro com Lisa, irá lançá-lo diretamente nos braços da mulher por ele desejada.

Essa cortina que isola os dois novos amantes dos olhares dos outros é somente um dos ressaltados sinais teatrais do romance (atrás de uma cortina, mais adiante, em situação oposta, Lisa irá se esconder, espiando Leo e Carla, e guardando para si o "inesperado segredo", que somente muito depois revelará a Michele, retirando metaforicamente a trava da sua pistola, e apontando-a contra Leo, alvo contra o qual não partirá nenhum golpe; o que coloca à mostra, portanto, a impotência de Michele diante de toda ação).

A luz é importante, ou, como se diz no teatro, as luzes; das quais, na gama que vai da penumbra ao ofuscamento, Moravia coloca em ação todos os refletores, com freqüência acionando uma só lâmpada por vez, para envolver no facho de luz o personagem central das cenas particulares, jogando com o chiaroscuro segundo um gosto cujo sentido se revela a partir do nome de Pirandello, citado nas primeiras páginas; depois haverá outras luzes, a luz que chove sobre as coisas, o dia, ou melhor, o céu branco da manhã na casa de Lisa e durante o banquete, e assim por diante.

As luzes servirão também para falar da aproximação do autor com a multidão que está fora do mundo dos seus personagens, na única aparição que essas pessoas fazem no romance:

As calçadas estavam repletas de uma viva multidão de trabalhadores de toda espécie que voltavam para suas casas; o sol frio de fevereiro iluminava suas faces avermelhadas pelo vento gelado, sob as abas usadas dos chapéus descoloridos e disformes, e os seus corpos fechados nos sobretudos esverdeados pelo tempo; era um fraco sol branco e sem calor que se difundia generosamente sobre todos aqueles andrajos, como se quisesse abençoá-los.

(como não recordar, atraídos por essa benção, o sol e a brisa que acompanham frei Cristoforo na saída do convento de Pescarenico, entre o doloroso "espetáculo dos trabalhadores espalhados nos campos" e as vacas emagrecidas?).

Em seguida, os ambientes: o reconhecimento dos vários pontos da casa (sala de visitas, sala de jantar, corredor, vestíbulo e os quartos) é completado ao se passar de um capítulo a outro, como para se dar tempo para a mudança de cena. A primeira externa acontecerá no jardim, no encontro que ocorre no capítulo sete entre Carla, ébria, e Leo.

Enfim, a indumentária: o vestido de Carla, o velho traje de Michele, elogiado por Leo, o penteado e a maquiagem de Mariagrazia (a um certo ponto do romance será dito 
que havia "empoado de novo a face"; ao final, para o baile dos Berardi, ela irá se fantasiar pateticamente de espanhola, sem compreender nada da filha e de Leo; ao seu lado Lisa, "de uma brancura farinhosa, toda vestida de claro", com uma "carne rósea e loura" que excita brevemente Michele, mas logo depois o desagrada; por fim Carla fantasiada de Pierrot, contente de si, noiva de Leo), o sobretudo, turquesa como o traje de Michele, e a veste de Lisa. De Leo nada se diz, como se para ele fossem suficientes, para vesti-lo, gestos e palavras: irá se "maquiar", "cuidadosamente barbeado, empoado, penteado", somente quando vai para a cama com Carla. Mas o seu traje atrairá a atenção de Michele durante uma discussão, e bloqueará a ação do outro.

O capítulo dois inicia com um relevo cromático onde os objetos aparecem revisitados, primeiro através de uma rudimentar escultura (rudimentar porque apenas acenada, fictícia, teatral), depois por meio da pintura e da indicação da quarta parede.

Sob o lustre de três braços, o bloco branco da mesa cintilava com três miúdas faíscas de luz, os pratos, as jarras, os copos, exatamente como um bloco de mármore apenas riscado pelos cinzéis; havia manchas, o vinho era vermelho, o pão marrom, uma sopa verde fumegava no fundo das tigelas; mas aquela brancura as anulava e resplandecia imaculada entre quatro paredes sobre as quais, por contraste, tudo, móveis e quadros, confundia-se em uma única sombra negra.

O capítulo do despertar de Lisa e do seu encontro matutino com Michele, ao contrário, será assinalado pelas aquarelas, que primeiro se revelam em cores tênues e naturais (através do "orvalho adivinhavam-se as cores vagas, tênues e puras, um branco, um verde como que dissolvido em um lago de água"), e depois aparecem sobre as paredes da casa da mulher. No mesmo capítulo encontramos intensificada e explicitada a relação estreita entre luzes, indumentárias e máscaras, nos pensamentos de Carla: havia "a mesma luz sem ilusões e sem esperanças, particularmente costumeira, gasta pelo uso, como o tecido de um vestido, e tão inseparável de suas faces”.

Carla diz isso para si mesma, pensando na vida que não muda (não mudará nem mesmo quando imaginar que conquistou outra vida, depois da noite de amor com Leo); do mesmo modo Michele pensa na própria indiferença, antes mesmo de ser indiferente, e isso lhe impede de pronunciar ou gritar as revoltosas frases que gostaria, enquanto se limita a alguma descortesia burguesa. São esses pensamentos sobre a vida imutável e as frases não ditas que levam diretamente ao coração romanesco de Gli Indifferenti. Apesar dos gestos, representados como indicações de um diretor, apesar da unidade de tempo, apesar da cenas em um lugar fechado, apesar de tudo, permanecem as zonas mentais dos personagens a fazerem do romance, que só pode exprimi-las, um romance desde o início, sem possibilidade de mudá-lo para alguma outra coisa.

La folle journée de Gli Indifferenti, um par de dias, para ser preciso, de atos incongruentes e equivocados, de sátiras teatrais (Leo e Carla escondidos atrás da cortina e, posteriormente, fazendo Mariagrazia acreditar que estiveram o tempo todo no cômodo; Lisa que afirma ir dar um telefonema, mas não o faz, como percebe Michele), de simetrias que não se reencontram, a partir da assimetria inicial dos cinco personagens, três do sexo feminino e dois do sexo masculino, um dos quais amou ou ama todas as três mulheres, o outro que 
não consegue amar profundamente nenhuma; três que fazem parte de uma mesma família e dois que minam e dissolvem os fundamentos frágeis dela (e os corolários: Mariagrazia que, para evitar o encontro de seu amante Leo com a ex-amante Lisa, lança-o nos braços da futura amante Carla; a higiene matinal das mulheres, Lisa e Mariagrazia, que se cruzam com os amantes); o jardim da mansão, enfim, sugerem curiosas coincidências mozartianas no romance, captadas por toda a trilogia de Da Ponte: incluídas as simetrias de Cosi fan tutte, sem falar da velhacaria dongiovannesca de Leo ("Ainda que casado, você será sempre o mesmo Leo" é a sua marca final); ou de Fígaro, disputado por duas mulheres, tensão resolvida por "mil dobles" no momento oportuno, enquanto o dinheiro, em Gli Indifferenti, não chega nunca.

Há ainda o bilhete de Leo a Carla ("Te espero dentro de uma hora...”), e a distração de Carla que, depois de "um sono vazio, negro como o breu", não se lembra mais de onde o colocou, fantasia sobre aquela escrita, interroga-se sobre a hora, até que o encontra entre seio e blusa, enquanto se abraça ao amante e, por não querer que ele seja lido, suscita uma cena de ciúme feroz, que logo depois será de vergonha. Um bilhete é também a desculpa com a qual Mariagrazia, suspeitando de Lisa, entra na casa de Leo assim que Carla havia ido embora. Um misterioso tom burlesco, um cômico cruel subterraneamente perturba todo o drama de inocência e de irresponsabilidade, mas também de culpa inexprimível, e de peso, tédio, impotência.

Que Gli Indifferenti possa, no entanto, ser considerado uma tragédia é constatação evidente, apoiada sobre evidências substancialmente clássicas: poucos personagens que falam sem necessidade de suportes ou comentários, e a apresentação dos conflitos da existência nas suas irresoluções. No entanto, não seria um erro dizer que Moravia, renunciando ao final da tragédia (a pistola não dispara), renuncia também ao propósito final, evitando a catarse, no sentido tanto aristotélico, quanto psicanalítico. Ali onde o esquema clássico da tragédia preveria uma calma que tivesse afugentado as tensões, Gli Indifferenti deixa pressentir outras tensões, velando as soluções com desdobramentos entre cômico e grotesco (o matrimônio prenunciado não é catarse, mais que isso, é um posterior evento trágico; talvez a tragédia aconteça fora do texto, quando Mariagrazia souber, ou quando as núpcias não ocorrerem).

O ponto que deveria ser trágico por intensidade, o homicídio de Leo por parte de Michele, é um ato equivocado e ridículo, que funciona somente quando Michele se contenta em imaginá-lo, em uma fantasiosa grandeza, em sua "fome árida de tempestade" que ignora ou idealiza a realidade sem nunca apreendê-la, impedido de viver ao ponto de ser impossibilitado de odiar: ele racionaliza a aversão a Leo, e nem mesmo quando tenta matálo, o instinto o domina; assim o revólver parece rebelar-se, emperra, produz uma brincadeira deslocada.

Mesmo desta vez, tendo falhado o homicídio, "Carla entrou", vestida como em uma variação de si mesma: "Não usava jaqueta, vestia uma saia justa e uma malha de lã marrom; devia ter se vestido às pressas”. E de fato Leo havia pedido que ela não aparecesse, que permanecesse escondida. Michele, pelo contrário, é ele mesmo, sem variações: "onde estaria o desdém virtuoso que tinha imaginado experimentar em tal momento?" ("em tal momento" é expressão apreciada pelos livretos de melodrama). O desfecho, o matrimônio de Leo com Carla, é momento de pena muito mais que de serenidade. 
"Entrou Carla", portanto, com seu pequeno vestido de lã marrom e, fechando a porta, a sua saia curta subiu rápida sobre as meias. Imaginando-se casada com um Merumeci "um pouco mais calvo, um pouco mais gordo, mas não muito mudado", que só não se curva mais em direção a ela, porque está sentado ao seu lado, ela acaba sendo menina, mesmo na sua roupa de noite. No capítulo das peregrinações de Leo, o sétimo, muito chuvoso para se ir dançar no Ritz, quando Leo a vê estava próxima a uma lâmpada, a única acesa: "sentada e imóvel; estava pronta para sair, usava um leve vestido cor de pêssego, estava empoada, penteada e maquiada", um vestido inocente em conflito com a sua máscara de adulta; agora "mantém as pernas cruzadas, fuma... efeito de pernas, o vestido é curto, o decote é profundo".

Efeito de pernas: o teatro está já se tornando cinema (pois os pensamentos de Mariagrazia, depois do encontro com Lisa, são "cinematografias", e "o cinematógrafo" das ambições de Michele "girava sempre mais rápido"), visto que mudam também os jogos de luzes, uma vez que Carla evoca a cor dominante: "é como uma prisioneira liberada que revê enfim a luz... a sua alegria é branca, todo o cômodo é branco".

Acrescente-se que, depois do seu primeiro ingresso na casa de Leo, aos olhos do amante Carla permanecia da mesma cor: "branca como a cera sobre o fundo escuro do divã", e recorde-se "aquele branco fantasma, aquele branco langor que das janelas veladas fluía no quarto, apertava o seu coração trêmulo em uma mão enorme e inchada", logo depois de voltar para casa, após a noite passada com Leo. Aquele branco. E toda a chuva daquele chuvoso inverno. $\mathrm{E}$ as últimas luzes, os faróis do táxi "com o raio direto dos seus faróis acesos", com Carla que imagina, falando de amor consigo mesma, um banho de sol para o próprio matrimônio, enquanto "o automóvel era a sua vida, lançada cegamente na obscuridade".

O jovem Moravia mudou alguma coisa no século XX. " "Aquilo que fez, ela chama de alguma coisa’, pensou Leo”, diz o romance: dizer o que é, esse é o problema.

\section{Notas}

1 "Entrou Carla; estava usando um vestidinho de lã marrom com uma saia tão curta, que bastou aquele movimento de fechar a porta para fazê-la subir um bom palmo acima das dobras que as meias formavam em torno de suas pernas(...)". A. Moravia, Os Indiferentes, R.J., Bertrand do Brasil, 1988, p. 5. Trad. Álvaro Lorencini e Letizia Zini Antunes. [N. do E.]

2 Referência aos escritores italianos Alfredo Oriani (1852-1909) e Alfredo Panzini (1863-1939) [N.do E.]

3 Do qual não se poderá esquecer Troppo grano sotto la neve .

4 Impareggiabile $=$ incomparável; meravigliosa $=$ maravilhosa. [N. do E.]

5 A. Elkann e A. Moravia. Vita di Alberto Moravia, Milano, Mondadori, 1990.

6 Cf. ref. n.5.

7 Cf. N. Ajello, Intervista sullo scrittore scomodo, Roma-Bari, Laterza, 1978.

8 Cf. n. 7.

9 Cf. n. 5.

10 Cf. n.7.

11 New York, Laurel, 1960. 